\title{
CONSTRUCTION OF A BEARING TESTING APPARATUS T0 ASSESS LIFETIME OF LARGE-SCALE BEARINGS
}

This article discusses steps towards the design, construction and production of a device used for lifetime assessment of large-scale bearings. The machine is reviewed as a mechatronic entity, comprised of three parts - mechanical, electro technical and hydraulic. The mechanical part was designed with the help of modern CAD/CAE/PDM design systems along with device parts modeling and strength analysis of highly stressed device parts. The electrotechnical part consists of a driving unit - containing the frequency transducer and an asynchronous motor; the PLC-driven operating part together with a touchscreen interface and a monitoring part which includes a datalogging device to record measurement results and interface with a PC.

\section{Introduction}

Electricity from renewable power sources plays an important part in today's world. One such example is energy obtained from wind power. Wind energy has evolved quickly since the seventies during the oil crisis and still continues. Wind energy accounts for $2 \%$ of all energy produced in Europe, while in Germany almost $5 \%$ and in Denmark $20 \%$ of all energy is produced from wind. More than $80 \%$ of all wind turbines are produced by European companies, which is evident in the high number of installations (approximately $85 \%$ of all installations are located in Europe). [1]

Most common wind generators are tri-blade type with a vertical axis. Most turbines are capable of changing the orientation of the blade part based on wind direction. Large wind turbines usually generate tri-phase alternating current, which is then run through a transformer located nearby or directly on the turbine structure. Electricity is then transported similar to other power sources. [1]

One of the largest producers of wind turbines is a company called Vestas [2] that produces wind generators for power range between $850 \mathrm{~kW}$ to $3 \mathrm{MW}$. Wind generators are usually installed into fields, located either on land or sea. The latter is important when considering more efficient wind turbines at locations such as sea shelve. Wind turbines have an average lifetime of 20 to 25 years. [1]

One of the main parts of wind generators is the rotor, upon which is placed the propeller. The rotor is placed in the stator part of the generator on two barrel bearings. Based on the power of the wind generator, the bearings used can have an outer diameter of two meters or more. PSL a.s. Povazska Bystrica [3] produces the mentioned bearing types. The bearing manufacturer must guaran- tee a bearing lifetime of at least 20 years. The bearing lifetime is based on accelerated lifetime tests. These tests require appropriate testing methodology and testing apparatus used to measure the lifetime of the bearings. The need for lifetime testing of these dimensionally-atypical bearings, exceeding the dimensions of standard bearing types, has led to a joint venture between the University of Zilina and manufacturer PSL a.s. Povazska Bystrica whose aim was to construct a testing apparatus aimed at evaluating the lifetime of bearings produced by the manufacturer.

\section{Testing apparatus design}

The testing apparatus design was based on a study aimed at testing special cone-shaped bearings with a maximum diameter of $1300 \mathrm{~mm}$, conducted by the manufacturer PSL a.s. The aim of the study was to design a testing apparatus capable of determining the following parameters: Rating life $L h v$ and Basic dynamic carryingcapacity $\mathrm{Cr}$ in a relatively short time, approximately three months from the start of the test. The object of the study were special coneshaped bearings with a maximum outer diameter $\phi=1300 \mathrm{~mm}$. The study also outlined testing methodology and definitions of parameters which respected the following requirements: Dynamic carrying-capacity of the said bearings $\mathrm{Cr}$, Rating life $\mathrm{Li} 10^{6}$ rev., rotational frequency 20 to $30 \mathrm{~min}^{-1}$, purely axial loading of the bearings and a testing interval not longer than 3 to 4 months.

With respect to the mentioned parameters, the methodology determined the maximum bearing load force with maximum dynamic carrying-capacity $(\mathrm{Cr}) 4000 \mathrm{kN}$ in the axial direction. The whole testing apparatus was rated according to this loading force.

The study took into account two types of force exerted onto the bearing. The first consisted in mechanical calculation of the

\footnotetext{
* Slavomir Hrcek, Vaclav Kraus, Robert Kohar, Stefan Medvecky ${ }^{1}$, Pavol Lehocky ${ }^{2}$

${ }^{1}$ Faculty of Mechanical Engineering, University of Zilina, Slovakia, E-mail: slavomir.hrcek@fstroj.uniza.sk

${ }^{2}$ Faculty of Electrical Engineering, University of Zilina, Slovakia
} 
axial force be means of diaphragm springs. The second consisted in calculation by means of a hydraulic cylinder. Both alternatives were considered, however it was agreed that the mechanical calculation had numerous disadvantages. Load force setting would also be problematic, reaching values around $4000 \mathrm{kN}$. Also load force monitoring would be very coarse because considering the fact that when using plate springs the force is not directly proportional to the deformation. Calibration of such force would also be complicated and expensive. For these reasons it was agreed not to use this method.

Instead, the second method based on hydraulic load force calculation with a double acting hydraulic cylinder was used. The study considered the use of a single hydraulic cylinder which would determine the force exactly in the axis of the mounted bearing. This configuration would require a massive support which would intercept the reactive force from the loading force, requiring the use of massive profiles when constructing the support and additional technical complexity when welding and problematic fixation on the ground. Because the location of the hydraulic cylinder and support would be in the axis of the tested bearing, manipulation with the bearing and fastening accessories into test state would require a crane (the weight of the said bearings exceeds hundreds of kilograms) or a loading device placed in the testing hall.

For this reason the hydraulic method was modified and the testing apparatus itself consisted of four smaller hydraulic cylinders placed outside the axis of the tested bearings.

\section{Mechanical part}

Modern CAD, CAE and PDM/PLM applications were used when constructing the mechanical parts of the testing apparatus. Pro/ENGINEER was used to construct individual components of the testing apparatus.

The basic idea behind the design of the testing apparatus was to place the tested bearing between two plates pressed against each other by means of four hydraulic cylinders. This arrangement is advantageous due to the fact that it is a closed system and no reac- tive force is transferred outside this system. The bearing is placed between these two plates and attached onto the clutch of an electromotor with gear which provides the bearing movement.

The lower plate has a square profile with a width of $140 \mathrm{~mm}$. The bottom part contains the electromotor with gear, the four hydraulic cylinders are placed in the corners and the upper part contains the fastening accessories for the tested bearing. Strength analysis in CAE system Ansys/Workbench showed that the base plate ends would bend under the force exerted by the hydraulic cylinders. To overcome this problem, ring-shaped stiffeners were placed near the hydraulic cylinders, which were then welded to the bottom part of the plate, lowering the total deformation to an acceptable level. The diameters of the cylinders were optimized thanks to the interconnection between Pro/ENGINEER and Ansys/ Workbench, defining optimization with the main goal of finding acceptable strain levels by means of variation of the diameter of the additive rings.

The upper plate was originally designed as massive weldment of the plate and four cross-placed ribs, containing openings to place pivots through the eyes of hydraulic cylinders. However, from a technological point of view, this concept was disadvantageous because of the complexity when welding the upper plate and the resulting finishing of the functional areas would be uneconomical in view of the budget allocated for the testing apparatus. To this end, the construction of the upper place was modified and an assembly system was used. This change required modification of the plate, which was also optimized in Ansys/Workbench using the finite elements method with criterion of allowable strain.

Because of time restrictions and the loading method used, the testing apparatus was designed in such a way so as to allow the concurrent testing of two bearings of the same type oriented against each other. A fastening apparatus was designed to place the bearings into the testing apparatus. The inner rings of bearing were fitted to the central shaft, which was connected to the output axle of the gear via a clutch with involute splining. This arrangement allowed for the shifting of the axle with inner rings in the axial direction. This shift is caused by the pressing of tested bearings in the axial direction. The outer rings of the bearings are placed in
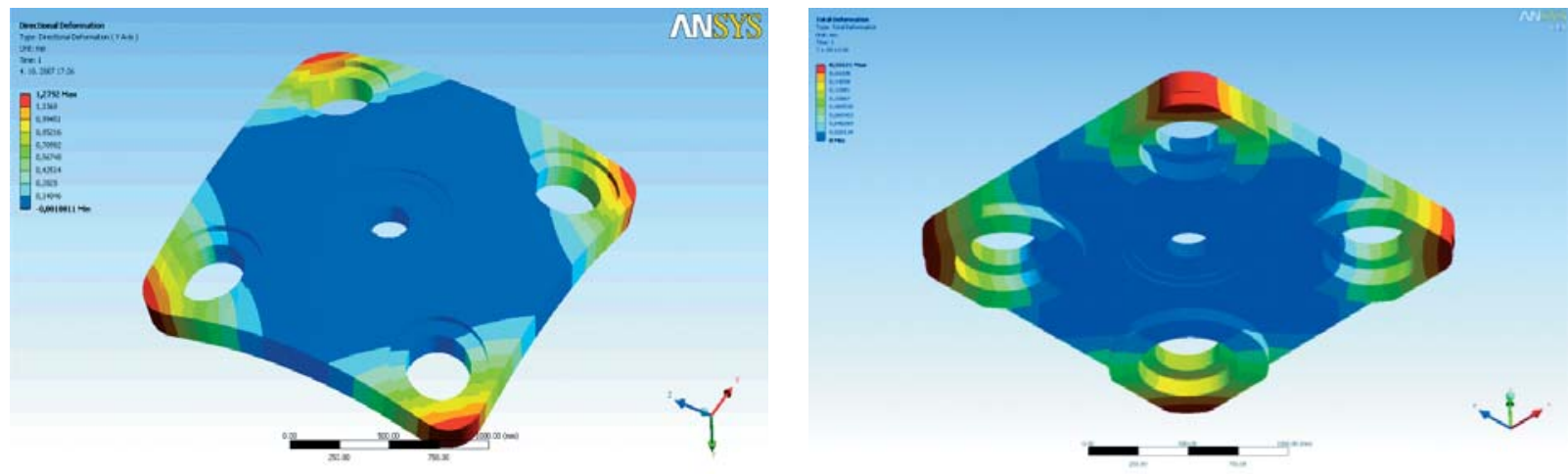

Fig. 1. Strength analysis of welded bottom plate 

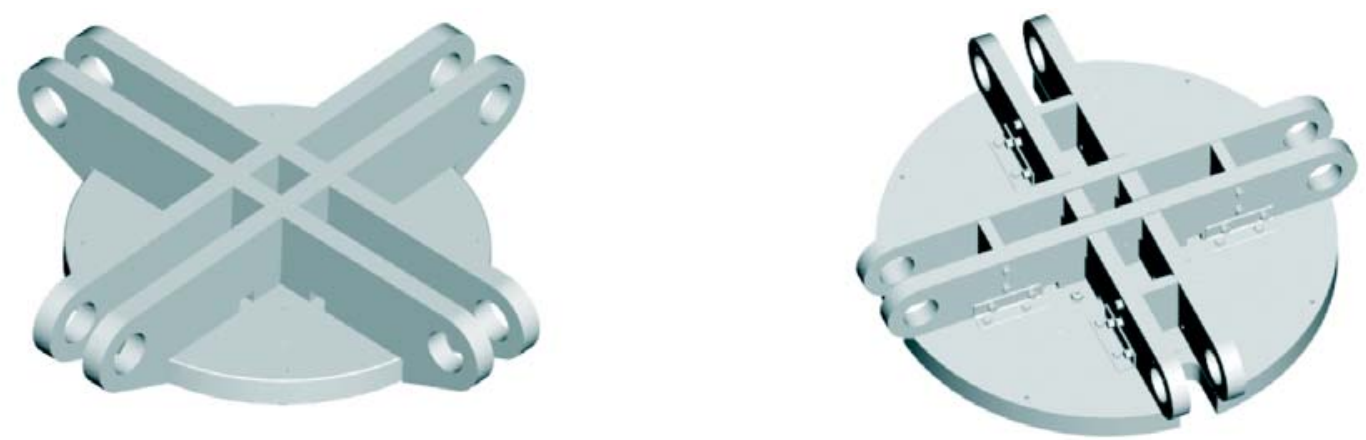

Fig. 2. Upper plate constructional modification

two rings which contain temperature and vibration sensors and the output sensor data were used in the evaluation of the bearing life-time.

The study requested the possibility to replace the tested bearings from the fastening apparatus to change the same bearing type to repeat the test. However this is not possible because the fastening apparatus was designed with clearance fit for the inner bearing rings and axle and also the outer bearing ring and outer rings. This arrangement does not correspond to real-life arrangements and leads to the destruction of the outer ring of one of the tested bearings. For this reason a separate fastening apparatus will be manufactured for each tested bearing set with overlapping identical to the real-life conditions used in wind-generators. The dismantling of the bearings from the fastening apparatus will however be very complicated, if not impossible. Real-life conditions are nonetheless more important criterion when testing the life-time of bearings.

\section{Electrical part}

To assure the function of the testing apparatus, the mechanical part must be complemented by appropriate electrical part, such as driving units used to launch all mechanisms and units that regulate and operate driving mechanisms based on the testing methodology. The designed apparatus has a testing state function and this requires the monitoring and recording of the measured data. The complete electrical part of the device can also be called the electric outfit of the machine.

The electric part of the designed device can be divided into the following parts:

- power (force) part: this part includes bus-bar, belaying and switching elements, frequency transducer, which drives the main gear of the testing state and ensures constant RPM during the whole test a gradual startup and shutdown or immediate stop in case of emergency state. The force part also includes the power supply of the pumps used in the hydraulic device and drive of the ventilator and pumps of the cooling assembly. Each device is powered by the required voltage, in this case either $230 \mathrm{~V} 50 \mathrm{~Hz}$ or $24 \mathrm{~V}$ DC from a switching supply,

- control part, which consists of a PLC automat, input control elements (buttons, touchscreen), transducers, output - action elements (electromagnetic valves of the hydraulic device, switching elements of ventilators and cooling pumps, input control part of the frequency transducer regulating the RPM, stop, start, emergency stop of the main traction, relay, signalization...),
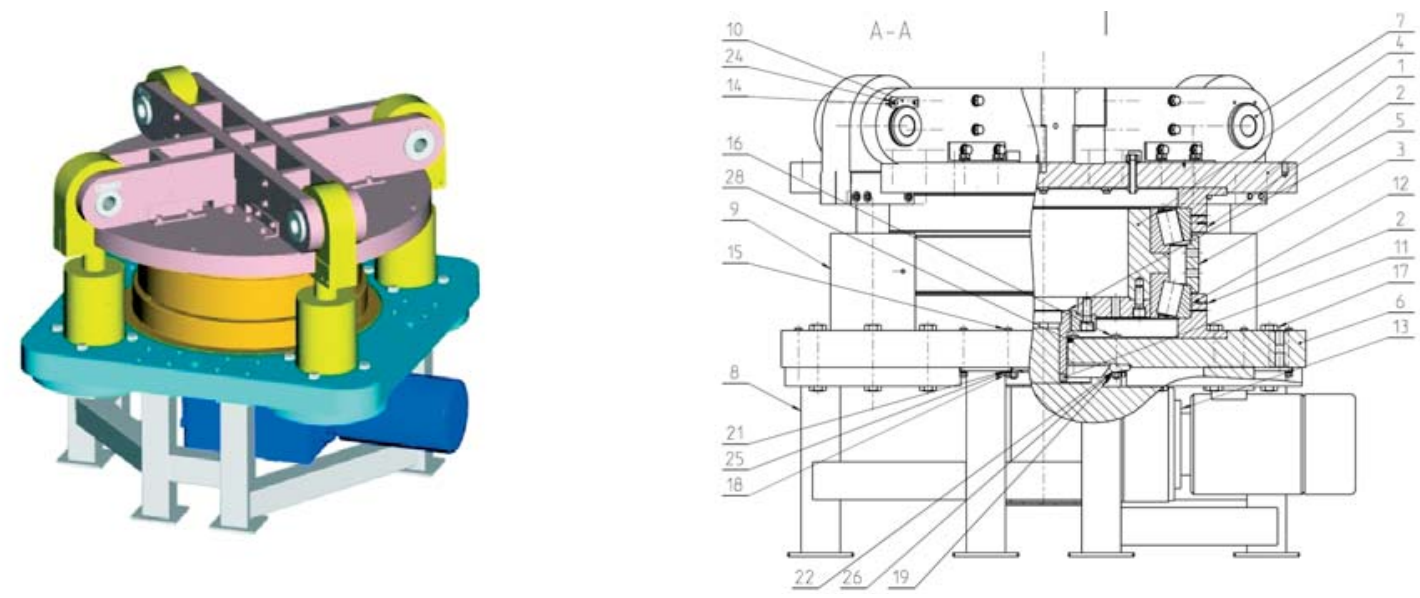

Fig. 3. Testing apparatus for special large-scale bearings 


\section{COMMNICOIIONS}

- monitoring part containing certified pressure transducers, temperature, vibration, time and datalogger. This part also includes a PC.

The electric part was designed based on the following:

- input voltage - 3PEN $\sim 50 \mathrm{~Hz} 400 \mathrm{~V}-\mathrm{TN}-\mathrm{C}-\mathrm{S}$,

- operating environment - normal, according STN 330300 čl.3.1.1 standard.
The design of the electric outfit of the machine of the testing apparatus contains the design of the mechanical arrangement of the distributor, including the electrical connection of devices within the said distributor, electrical connection of devices placed on the testing state and design of the datalogger. The following figure shows the block scheme of the device.

The design of the electromotor and the associated parameters, such as power, RPM, torque etc. are based on the following

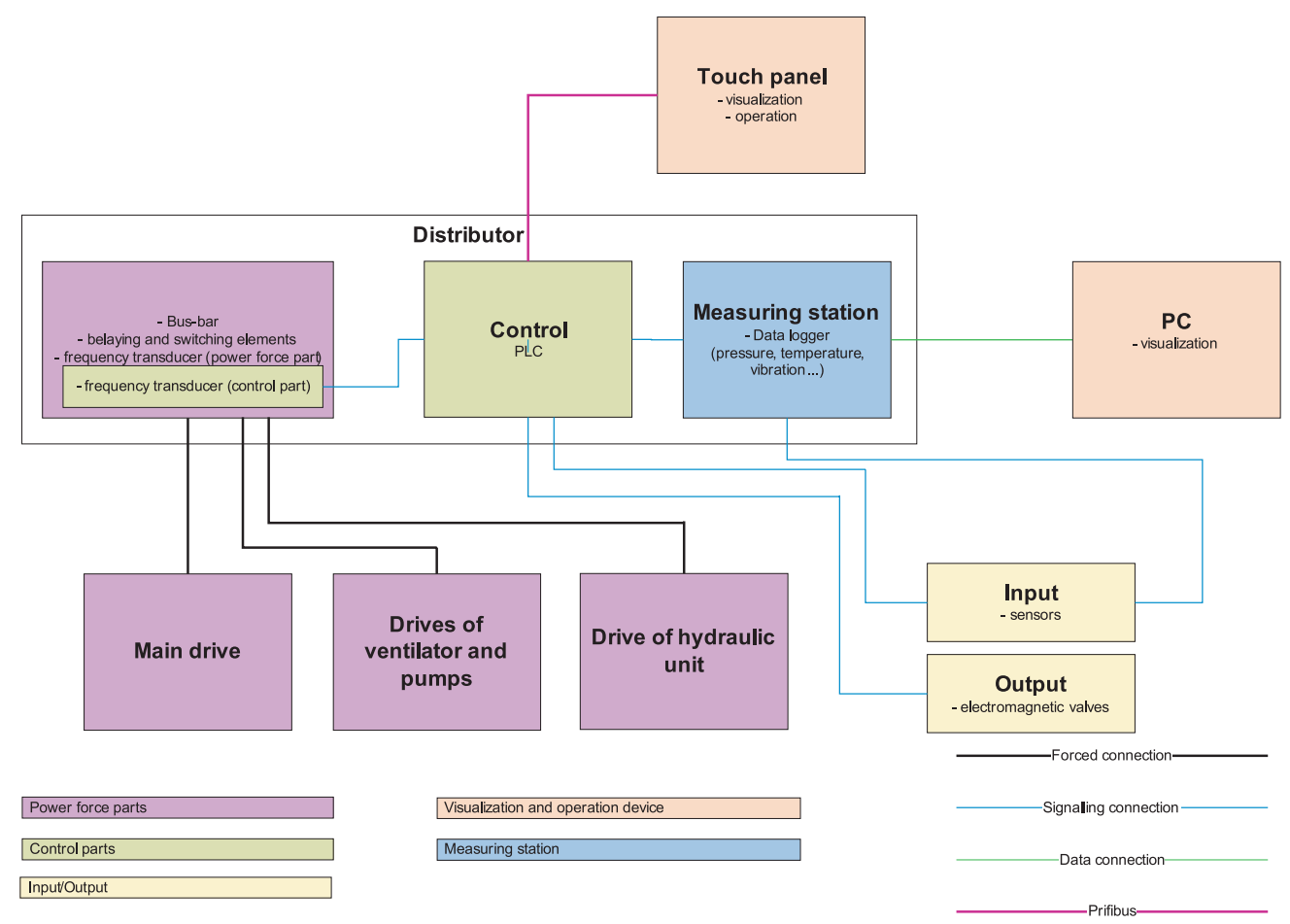

Fig. 4. Block scheme of the device
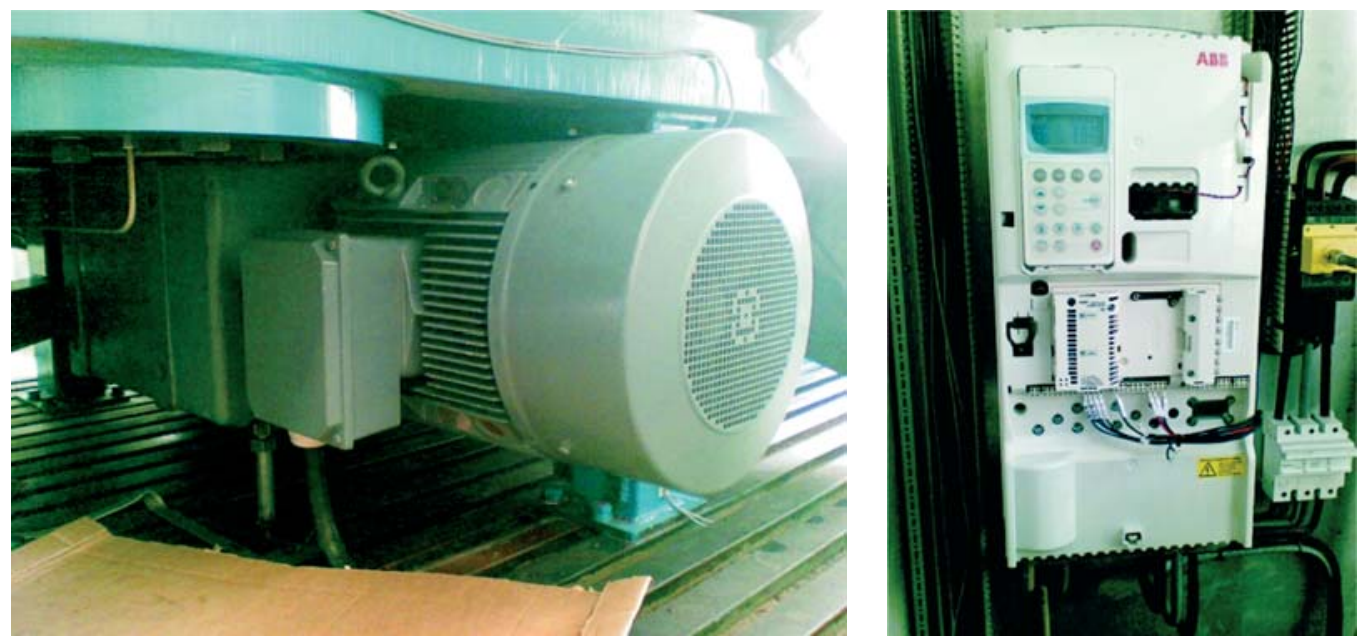

Fig. 5. Asynchronous motor with a bevel-spur gear, frequency transducer 
conditions: maximum RPM of the tested bearings should be 40 $\mathrm{rev} . / \mathrm{min}$. with a maximum load of $4000 \mathrm{kN}$ and the total central momentum of the system must be calculated to the electric drive output shaft. It is also necessary to assure that the electric drive is capable of achieving the required RPM under load within the required time without overloading the motor. An asynchronous motor with a bevel-spur gear shaft was used in the design to assure a safety coefficient of 1.3 .

Parameters of the asynchronous motor:

- power output: $55 \mathrm{~kW}$,

- nominal current at 400V: $8.1 \mathrm{~A}$,

- nominal revolutions: $1460 \mathrm{rev} . / \mathrm{min}$,

- nominal moment: $26.9 \mathrm{Nm}$.

Gear parameters:

- gear ratio: 5.64 .

The asynchronous motor and gear are used to drive the tested bearings through a toothed pinion. The motor is fed via a frequency transducer with direct torque control (DTC). A frequency transducer was necessary because the test state required changes in RPM together with fluid start-up a shutdown along the set rise and fall ramp. The used frequency transducer is manufactured by ABB company, type ACS 800-03E-08A8-4 with the following parameters:

- power output: $4 \mathrm{~kW}$,

- nominal current $8.8 \mathrm{~A}$,

- input voltage $\mathrm{Un}=400 \mathrm{~V}, 50 \mathrm{~Hz}$.

This frequency transducer is placed within the distributor. Other electric devices, such as terminal blocks, fuses, contractors, fuses, 24V DC switched power supply, PLC automat, 230V technological power plugs, datalogger etc. are also placed within the distributor.

An operating unit is used to automate and allow for independent test state execution without the need for human interaction. In this case the SIEMENS S7-CPU224XP PCL automat was used, alongside two expansion modules: EM223 adding digital I/O ports

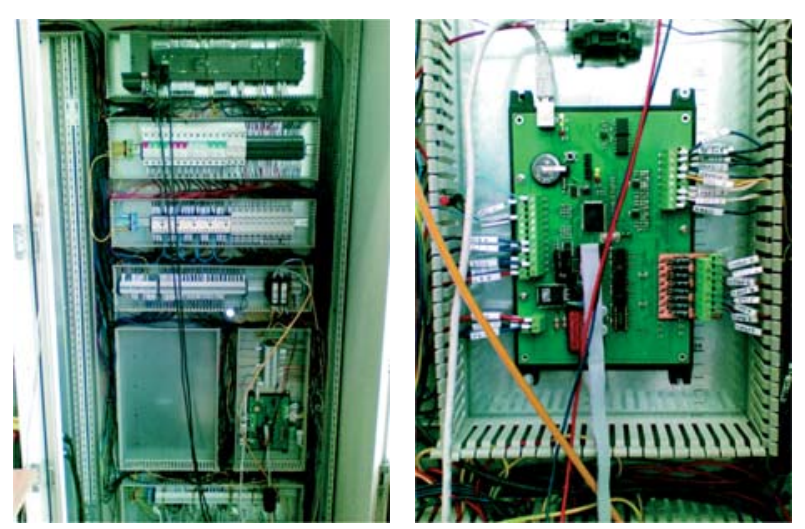

Fig. 6. Layout of the distributor, datalogger and EM235 adding analogue I/O ports. The PLC automat registers input signals from sensors and switches outputs connected to action units or signalizations. The outputs are switched according to pre-programmed sequences based on the test progress. The mentioned SIEMENS PLC automats (S7-2xx) are programmed in the Step7 - MicroWin programming environment. This software tools allows for the development of virtual logical circuit (PLC automat programming) used to control the device. In the past these logical circuits were built using mechanical switching components - relays, which caused frequent malfunctions, the circuits were complicated, required much maintenance and subsequent modification and changes of work sequences were was limited. However because PLC automats allow the creation of virtual logical circuits it is possible to debug, verify and if necessary also change the circuit without the need for mechanical changes.

A touchscreen (TP177Micro ) was used to reduce the number of mechanical inputs (buttons, switches) and output signaling elements (LED, lighting columns). The PLC automat is connected with the touchscreen via a communication bus (PROFIBUS). The test state can be controlled via the touchscreen and also allows for visual monitoring (graphical symbols or text) about the device state.

Sensors installed in the testing state can be divided into two groups. The first group contains sensors which assure the functioning of the testing state and safe operation thereof. The following sensors are present:

- pressure sensor in the pressure battery,

- security sensor of minimum pressure in pressure battery,

- hydraulic oil temperature sensors,

- sensors of hydraulic oil levels in the oil tank,

- sensors of hydraulic oil filter clogging,

- sensor of lubricating oil temperature in the tank,

- sensor of lubricating oil levels in the tank.

The outputs of these sensors are in digitized form and are fed to the digital input ports of the PLC automat. This group also includes sensors which detect impacts in the tested bearings. The output of these sensors is fed to converters which provide output current within the $4-20 \mathrm{~mA}$ range which is then fed to analogue input of the PLC automat. The time variation of impact in the tested bearings is shown on the touchscreen in units of decibels.

The second group consists of sensors which measure quantities associated with the bearing test. The following sensors are present:

- sensors of outer bearing rings temperature,

- sensor of environmental temperature,

- sensor of temperature of input lubricating oil,

- sensor of temperature of output lubricating oil,

- sensor of pressure within the hydraulic system,

- vibration sensors.

These sensors have analogue outputs. Sensors of outer bearing rings temperature and environmental temperature are produced by type $\mathrm{K}$ thermocouples. Their output is in the form of voltage. Output of sensors recording vibration speed is fed to converters 
which provide output current in the $4-20 \mathrm{~mA}$ range. Output from other sensors is in the $4-20 \mathrm{~mA}$ range. The output quantities of these sensors must be recorded because they are necessary in the testing procedure. Thus, the output from these sensors is fed to analogue inputs of the datalogger, including the digital signal from the inductive sensor which is used as incremental counter of the number of revolutions.

The datalogger is a device whose purpose is to log and archive the obtained sensor signals. In our case the datalogger is designed based on a personal computer and the measuring board. The hard disk is used as recording medium with the aim of archiving measured data. The designed measuring board used analogue inputs which can be configured to different voltage and/or current input ranges based on required conditions and the sensors used. In addition to the mentioned analogue inputs the card also contains digital I/O ports. Digital ports are used to control the board or inform the system of specific test states. In our case signals from the PLC automat are fed to the board and the board output is then fed back to the PLC automat. This measurement board is equipped with a digital signal processor (DSP), which controls the board,
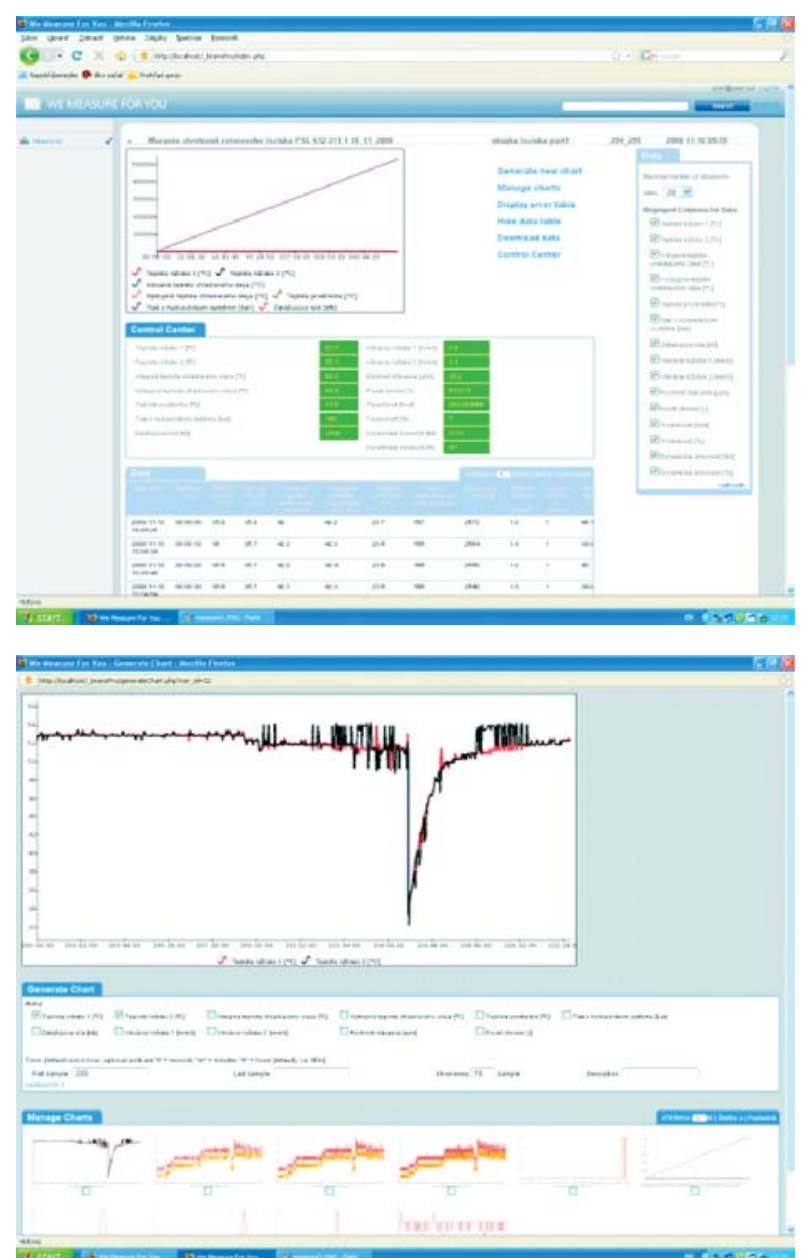

processes the measured data and assures communication with the computer via USB ports.

A driver was programmed to enable communication between the board and the used operating system (Windows XP). This driver is part of the so-called "Datalogger manager" application which has the following use:

- setup hardware parameters for the mutual communication between the operating system and the measurement board,

- control the functioning of the measurement board (measurement start/stop...),

- output the board state and measured quantities onto the computer monitor,

- write acquired data from the measurement board into a database.

The My SQL database system was used due to the number of recorded quantities and the overall test length.

An application was developed to allow not only local but also remote monitoring of the acquired and current test data through
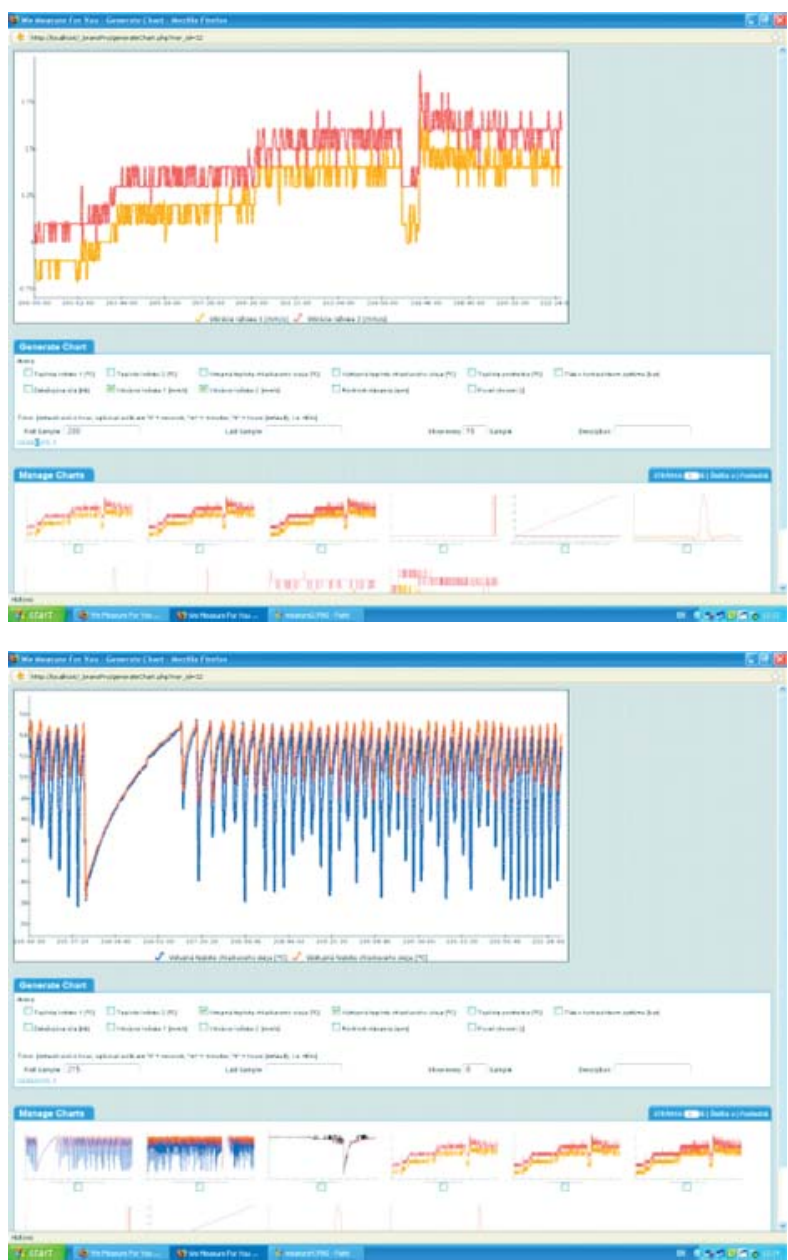

Fig. 7. Web interface allowing data assessment 

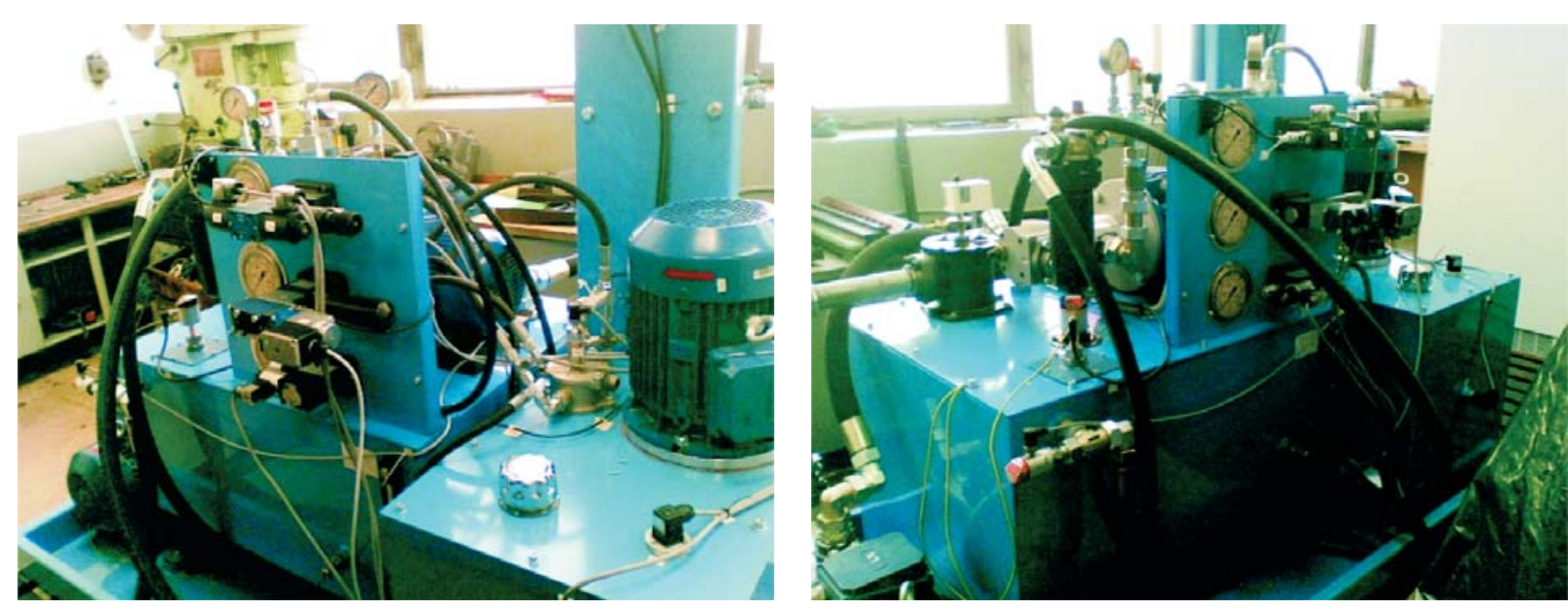

Fig. 8. Hydraulic assembly of the testing apparatus

web interface. This allows any user with access to the internet and the necessary credentials to acquire or browse the measured data.

The application itself contains administrative and user access. The first allows the user to save the measurement. This includes the creation of a new measurement with defined test duration and sampling intervals, choice of monitored quantities and definition of boundary conditions indicating critical or emergency values which result in test termination. Both accesses allow numeric or graphical examination of the recorded data. Individual graphs can be shown for different time segments and number of samples shown in the graph. The acquired time behavior can be saved in picture form onto the computer from which the user has logged on to the remote system database. Data contained in the database can be user-saved either as a text document or in excel data format (xls).

\section{Hydraulic part}

The hydraulic part of the testing apparatus is divided into two parts - the pressure part, assuring the required pressure in hydraulic cylinders and the lubricating part - assuring bearing lubrication during test execution.

Four hydraulic cylinders form the main component of the pressure part, designed in such a way that each cylinder is capable of exerting a pressure equal to $1000 \mathrm{kN}$. This application is typical of high pressure which is necessary to obtain the required loading force with small flow rate of the hydraulic oil. This allowed for the use of pressure sources with a constant pressure of 300 bar used to fill the hydraulic cylinders. By using pressure sources it was possible to eliminate the need for constant compressor use, which is used to guarantee system pressure. The required pressure change and the resulting load variations are effectuated during rise and fall time of the bearing test via proportional reductive valve. A mechanical reductive valve is set to the desired value and then used to control the pressure during the test execution. This approach was chosen to automate the bearing testing, where during rise and fall time based on the chosen approach the bearing is gradually loaded and unloaded. The gradual loading and unloading of the bearing is assured by a proportional reductive valve which varies the pressure according to the input voltage magnitude in the 0 $10 \mathrm{~V}$ range from the analogue output of the PLC automat. The proportional reductive valve is characteristic of high pressure losses which translate into frequent pump activation. For this reason the system is switched to the mechanical reductive valve once the required pressure has been reached, resulting on lower pressure losses. This is conditioned by the following criterion: the value of the mechanical reductive valve must be equal to value of the proportional reductive valve at the time of switching. Change of direction of the hydraulic cylinders piston movement is effectuated via switching of the appropriate valve which conducts the hydraulic oil before or after the piston of individual hydraulic cylinders.

The lubricating component of the hydraulic part assures sufficient lubricating texture on the running surface of the tested bearings and to regulate temperature of the bearings within the operating conditions. The lubricating oil is pulled from the reservoir using a pump and passed through a filter and eight nozzles directly onto the running surface of the bearings. The oil flow rate must be equal to $50 \mathrm{l} / \mathrm{min}$ to achieve optimal lubricating and cooling effects. The oil residing at the bottom of the testing state must be pumped back to the reservoir due to its high viscosity. Oil levels in the reservoir are monitored via level meter. Oil levels beyond or below the selected threshold indicate malfunctioning of the lubricating system requiring the stoppage of the testing state.

This lubricating part also contains a cooling circuit. If the lubricating temperature exceeds the specified value, a pump is activated and pulls the lubricating oil from the reservoir into the cooler. This cooler is equipped with a ventilator. The cooling cycle is terminated once the temperature of the cooling oil drops to the specified value.

Operation of the hydraulic part is assured by the PLC automat according to preprogrammed sequences. 


\section{Conclusion}

The University of Zilina cooperated with PSL a.s. Povazska Bystrica to develop, construct and build a testing state for testing special, large-scale barrel bearings. Using modern CAD, CAE and PDM systems it was possible to construct this device in relatively short time and components were developed simultaneously. Operation of the testing state is user-friendly and simple thanks to the use of a PLC automat. Automation allows bearings to be evaluated without interruption which is advantageous from a time point of view. This testing state is unique and perhaps one of its kind and allows testing of special, non-standard bearings. However other sensor types or sensors of different quantities can be used because the data logger design was designed with flexibility and universality in mind.

This work was supported by the Slovak Research and Development Agency under the contract No. APVV-0505-07

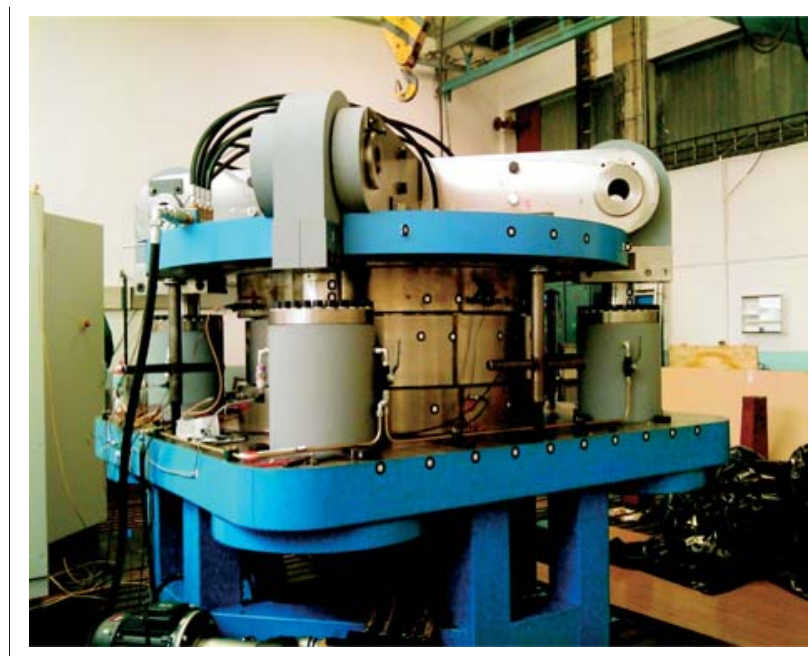

Fig. 9. Operation of the testing apparatus

\section{References:}

[1] http://www.ozeport.sk/zdroje/veterna.html

[2] http://www.vestas.com/en/wind-power-solutions.aspx

[3] http://www.pslas.com/sk/index.php 